Original Article

\title{
Feral Wild Boar Distribution and Perceptions of Risk on the Central Canadian Prairies
}

\author{
RYAN K. BROOK, ${ }^{\mathbf{1}}$ Department of Animal and Poultry Science $\mathcal{E}$ Indigenous Land Management Institute, College of Agriculture and Bioresources, \\ University of Saskatchewan, 51 Campus Drive, Saskatoon, SK, Canada S7N 5AB \\ FLORIS M. vAN BEEST, ${ }^{2}$ Department of Animal and Poultry Science E Indigenous Land Management Institute, College of Agriculture and \\ Bioresources, University of Saskatchewan, 51 Campus Drive, Saskatoon, SK, Canada S7N 5AB
}

\begin{abstract}
Feral wild boar (Sus scrofa) are rapidly expanding their distribution and abundance globally and causing considerable socio-economic impacts. Prior to this study, the spatial distribution of feral boar on the Canada prairies was largely unknown. We surveyed all 296 rural municipalities in Saskatchewan, Canada, to determine the distribution of feral boar in the province and characterize community leader perceptions of risk. Of the respondents, over the past 3 years $48 \%$ never saw feral boar, $48 \%$ saw them at least occasionally, and 3\% responded "I don't know," indicating a few respondents were not confident in saying feral boar were present or absent. Feral boar were observed across a range of habitats, in all months, and at all times of day. Variables that best predicted the distribution of feral boar included \% farmland ( $\beta=6.46), \%$ flaxseed crop ( $\beta=-8.63)$, density of paved roads $(\beta=-1.92), \%$ deciduous forest $(\beta=5.93)$, and $\%$ mustard seed crop $(\beta=-12.63)$. Mapping the resource selection probability function (RSPF) across the landscape of rural Saskatchewan predicted $70 \%$ of municipalities had RSPF $>0.7$ (high probability of boar presence) and $12 \%$ had RSPF $<0.3$ (low probability of boar presence). At the scale of the individual municipalities, responses about management actions were positively associated with frequency of feral boar observations, whereas questions about the province as a whole were consistently positive regardless of frequency of feral boar observations. Control efforts in Canada are sporadic and limited in scope and scale, but the current distribution of feral boar in Saskatchewan, in combination with the life-history strategy of the species, indicates that aggressive and coordinated action is required. (c) 2014 The Wildlife Society.
\end{abstract}

KEY WORDS Canada, disease, feral swine, invasive species, occupancy, perceptions of risk, range expansion, resource selection.

The feral wild boar (also called wild hog, feral swine, or feral pig [Sus scrofa]) is a highly invasive species originally native to Eurasia; it is now one of the most widely distributed species of large mammals in the world (Gipson et al. 1998, Leus 2008, Barrios-Garcia and Ballari 2012). It is well-established that wild boars were introduced to the continental United States in the 16th century (Towne and Wentworth 1950), but wild boar in Canada are much more recent arrivals. Domestic wild boar were introduced across western Canada to diversify agriculture in the 1980s and 1990s and they were first introduced to Saskatchewan during the 1990s as part of a broad initiative to diversify agricultural production (Wilkins and Dobbs 2013). Specific dates within Canada are not recorded and the timing and frequency of releases and escapes remains unknown. The initial domestic breeding stock for Canada originated in Great Britain, Poland, Germany, and Sweden (Saskatchewan Ministry of Agriculture, 2001). Past and current numbers of domestic

Received: 24 July 2013; Accepted: 14 December 2013

\footnotetext{
${ }^{1}$ E-mail: ryan.brook@usask.ca

${ }^{2}$ Present address: Department of Bioscience, Aarhus University, Frederiksborgvej 399 4000, Roskilde, Denmark
}

wild boar on the Canadian prairies have not been properly documented, in part because there are no licensing requirements. Domestic wild boar production has varied from a small number of relatively large-scale commercial farms to small scale "hobby" operations (www.statcan.gc.ca/ca-ra2011; Statistics Canada 2011). Although there has never been any formal monitoring of feral wild boar on the Canadian prairies, it became apparent from media reports in the 2000s that there were significant numbers of feral boar in parts of Saskatchewan, Manitoba, and Alberta.

The significant environmental and socio-economic impacts of feral boar are emerging as their numbers increase and their distribution expands across the globe. Damage to agricultural crops exceeds millions of U.S. dollars per year in many areas (Geisser and Reyer 2004) and livestock producers have reported feral boar impacts on domestic animals as well (Tegt et al. 2011). Feral boar are an important host for diseases and are able to transmit a wide variety of viruses, bacteria, and parasites harmful to livestock, wildlife, and humans (Forrester 1991, Samuel et al. 2001, Witmer et al. 2003). For example, Pseudorabies has been identified in 11 states and swine brucellosis has been found in 14 states so far in the USA (USDA-APHIS 2005), which greatly threatens the domestic swine industry. Impacts on native ecosystems have also been documented because feral boar trample and 
eat vegetation. Impacts can be especially high because of feral boar rooting and wallowing behavior, as well as contamination of water sources and impacts on rare and endangered species (Hone 2002, Jolley et al. 2010, Barrios-Garcia and Ballari 2012).

A key failure thus far in managing feral wild boar abundance and distribution in general, has been the prevalent assumption that this is a purely biological problem that requires only modified biophysical solutions and ignores or misunderstands the important social aspects of the problem. There are important interactions between social systems and ecosystems and the attitudes of local people have critical influences on the success or failure of wildlife management programs (Walker et al. 2004). Problems associated with the range expansion and impacts of feral boar (or any invasive problem species) are better described as a social-biophysical issue that includes both a biological aspect and an equally important social component. To be successful, management efforts should ideally involve an interdisciplinary integration of social and biological sciences that help us understand the role of habitat, animal ecology, and biogeography, as well as helping our understanding of the issues and concerns of stakeholders, their motivations, and perceptions of risk (Roe 1996, Brook and McLachlan 2009).

Prior to this study, there has not yet been any scientific effort undertaken to describe the distribution, resource selection patterns, management options, or local perceptions of risk related to wild boar in Canada. Indeed, we were unable to find a single peer-reviewed paper in the literature that provides empirical information on feral wild boar in Canada through searching Scopus and Web of Knowledge. As such, the objectives of this study were to 1) estimate the distribution of feral wild boar in rural Saskatchewan, 2) identify habitat factors at the scale of individual rural municipalities associated with boar presence, and 3) characterize community-based perceptions of risk associated with feral boar.

\section{STUDY AREA}

Our study area included all 296 rural municipalities in Saskatchewan, Canada, covering an area of $308,000 \mathrm{~km}^{2}$ that included the entire agriculture-dominated landscape of the province (Fig. 1). A rural municipality is an incorporated municipality (comparable to a county or township in western USA) that includes only rural areas, with towns and cities excluded. The rural municipalities in Saskatchewan averaged $1,040 \mathrm{~km}^{2}$ in size. The study area transitions from the Prairie Ecozone in the south to the Boreal Plains Ecozone in the north. The human population in rural areas of Saskatchewan totaled 174,530 people, with an average of 590 people in each rural municipality and an average human density of 0.57 people $/ \mathrm{km}^{2}$ (Statistics Canada 2011).

The majority of the study area was dominated by agriculture, especially annual grain and oilseed cropland (56\%), perennial forage cropland (13\%), and livestock production. Agricultural expansion over the past 150 years replaced $83 \%$ of the original provincial native grasslands with intensive crop production (Samson and Knopf 1994), leaving only 9\% of the area as

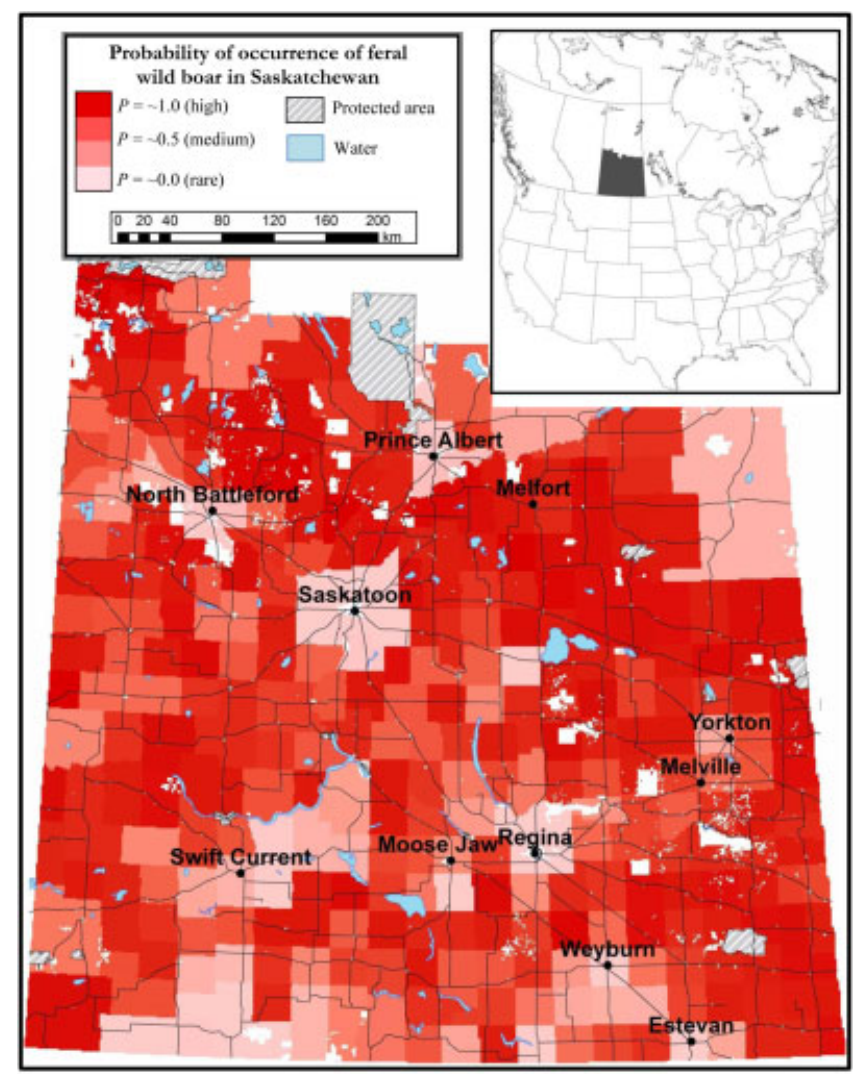

Figure 1. Probability of occurrence of feral wild boar in the province of Saskatchewan, Canada, based on Resource Selection Probability Function analysis of surveys of rural municipalities in the province conducted in January 2013.

grassland. Most of the remaining grasslands were used for grazing cattle (Veeman and Gray 2009). The study area also included $8 \%$ deciduous forest, $3 \%$ coniferous forest, $2 \%$ mixed deciduous-conifer forest, and $2 \%$ shrub land. The landscape is part of the Prairie Pothole region of the Great Plains, which is characterized by thousands of shallow pothole wetlands. These wetlands have also been significantly reduced and eliminated by agriculture and $3 \%$ of the landscape is currently wetland along with $3 \%$ of the landscape covered with water in rivers, ponds, and lakes. The remaining $1 \%$ of the landscape consisted of exposed gravel, sand, and built-up urban areas.

Within the study area, a "Wild Boar Eradication Fund" was established in 2009 to support a feral wild boar control program, funded at $\$ 50,000 /$ year (Canadian currency [CDN]) by the Saskatchewan Provincial Ministry of Agriculture and administered by the Saskatchewan Association of Rural Municipalities. The program funds a professional feral boar hunting and trapping team that will go to rural municipalities that make a complaint. Since its inception, the program has been under-subscribed, with only 3 rural municipalities, on average, utilizing the program each year. Beginning in 2010, Saskatchewan Crop Insurance Corporation added feral wild boar to the list of species for which they provide compensation for crop damage. This program provides $100 \%$ compensation for any claims confirmed by an adjustor for damage $\geq \$ 150$ CDN. However, from 2010 to 2012 only 21 
claims were made that were associated with feral wild boar, of which only 2 listed feral boar as the primary cause.

\section{METHODS}

\section{Survey Design}

In December 2012, we sent a survey (Supplementary Material available online) to all 296 rural municipalities in Saskatchewan by e-mail. The survey design was approved by the Behavioral Research Ethics Board at the University of Saskatchewan (BEH no. 12-356). We selected community leaders, in the form of elected municipal officials, for our survey as the ideal survey population for our study. Each rural municipality is governed by an elected council of a reeve (the chief executive) and, on average, 6 councilors as defined by provincial regulation that each represents the constituents of a sub-section of their rural municipality. The reeves and councilors are systematically distributed throughout the entire study area in all rural municipalities and in a stratified manner among divisions within each rural municipality. Furthermore, these locally elected individuals live within their divisions, travel extensively throughout their rural municipality, and through their work are among the individuals best connected to the people in their area; they regularly communicate and discuss with local people about diverse issues. These officials are also designated as contact persons for the provincial feral wild boar control program. As such, the elected officials are a reliable source of information about feral boar and local perspectives on the associated risks, because they influence control efforts and are likely an overall representative of the perceptions of the residents of rural Saskatchewan.

The council of each rural municipality was asked to complete the survey and return it by fax or mail. The survey included questions about feral boar observations, habitat associations and timing of these observations, presence of domestic wild boar farms, and perceptions of the community leaders regarding management options for feral boar (Supplementary Material available online). A reminder was sent to all non-responding rural municipalities 1 month later and a 6-question survey to test for non-response bias was conducted by phone with a sample of $10 \%$ of the rural municipalities that did not initially complete the survey.

\section{Modeling the Spatial Distribution of Wild Boar in Saskatchewan}

Characterizing the distribution of feral boar was based on the response to the question, "Are you aware of any observations of feral wild boar (not inside a fence) within your rural municipality in the past three years?" on a categorical scale; "never see," "rarely see," "see a few only on some days," "see a few on most days," "see regularly on most days," or "see regularly on all days." Since feral boar are relatively new to Saskatchewan and are nocturnal and elusive, we also included the potential response "I don't know," in the event that some respondents were not confident in saying feral boar were present or absent. To quantify the spatial distribution of feral wild boar in Saskatchewan, we used resource selection probability functions (RSPFs). RSPFs are based on presence-absence (or used-unused) data and are typically computed using logistic regression (MacKenzie 2006). In our case, rural municipalities in Saskatchewan were the sampling unit, with rural municipalities that reported observing boar within the past 3 years scored as 1 (present); while rural municipalities that reported not observing boar within the past 3 years scored as 0 (absent). As such, our RSPF analyses for wild boar in Saskatchewan were done at the population level (Design I: Manly et al. 2002, Thomas and Taylor 2006) and corresponded most closely to that of the first-order selection (i.e., physical or geographical range of a species: Johnson 1980).

Rural municipalities that did not respond to our questionnaire were excluded from the model-building procedure. Considerable spatial variation in the frequency of wild boar observations existed-some rural municipalities reported seeing "a few feral wild boar only on some days," while others reported seeing "a few feral wild boar on most days," or "feral wild boar regularly on most days" or "feral wild boar regularly on all days." Therefore, and to solve the logistic regression, we used generalized linear models and included a weighting structure for frequency of boar observations so that rural municipalities with high observation frequencies were given more weight than rural municipalities that observed boar sporadically. All analyses were performed in R (R Development Core Team 2013).

We initially considered a large number of potential explanatory variables for our RSPF analyses $(N=32)$. Vegetation types (coniferous forest, deciduous forest, mixed forest, native grassland, wetland, shrub land, non-vegetated areas, and water) present throughout the province were assessed using remotely sensed land-cover maps (100$\mathrm{m} \times 100-\mathrm{m}$ resolution) provided by Geobase Land Cover data (freely accessible at www.geobase.ca). Ground-truthing of vegetation types revealed that the accuracy of the landcover maps was satisfactory (van Beest et al. 2013). Using ArcGIS 10.1 and Geospatial Modelling Environment (Beyer 2012), we calculated the proportion of all vegetation types within each rural municipality. Using a digital elevation model $(30-\mathrm{m} \times 30-\mathrm{m}$ resolution), we also calculated the mean elevation and slope for each rural municipality. We used the kernel density estimator in Geospatial Modelling Environment (Beyer 2012) to calculate and map the density of paved roads, unpaved roads, and streams $\left(\mathrm{km}^{2}\right)$ across the province. We then used zonal statistics to extract the mean density of each variable (for further details see van Beest et al. 2013) for each rural municipality.

Wild boar are known to feed extensively on agricultural crops (Schley and Roper 2003). We therefore calculated the proportion of seeded acreage for 19 commercial crop species cultivated within the province. For this we relied on agricultural census data from 2011 (freely accessible at www. statcan.gc.ca/ca-ra2011; Statistics Canada 2011). We assumed that the proportion of seeded acreage did not change substantially between 2011 and 2013 at the scale of individual municipalities.

We employed several variable reduction techniques commonly used in large-scale occupancy modeling (Cooper 
et al. 2012). We first eliminated the number of commercial crop species that were present in $<40 \%$ of the rural municipalities (rare crop species: 12 crop species removed). Second, we transformed non-normally distributed variables to improve normality and removed all variables that were unable to be transformed satisfactorily (Shapiro-Wilk <0.10: 9 variables removed). Proportional variables were transformed with an arcsine square-root function (Crawley 2007) while continuous variables were log-transformed. Last, we screened for correlations and co-linearity among explanatory variables using Pearson's correlation and variance inflation factors. When 2 covariates were correlated or had high variance inflation factors (Pearson $r>0.5$ or variance inflation factors $>3$ ) we removed one of the covariates, retaining the variable with the strongest effect on wild boar resource use, as determined by single-term logistic regression. Another 6 variables were removed at this stage, which resulted in 5 explanatory variables considered in our full model (Table 1).

Model selection was conducted using a multi-model inference technique based on model-averaging (Burnham et al. 2011). We limited inference to a minimum number of non-correlated variables, so our set of candidate models consisted of all possible combinations of the final explanatory variables (Burnham and Anderson 2002). We considered models with $\Delta \mathrm{AIC}_{c}$ (i.e., the difference between the top ranked model and other candidate models, adjusted for small sample size) $<2$ to have substantial empirical support and calculated model-averaged coefficients and unconditional standard errors for covariates using the R library MuMIn. We also calculated the relative variable importance $[w+(j)]$ for each covariate by summing the Akaike's weights across all the models in the set where variable $j$ occurred. The larger the $w_{+}(j)$, the more important variable $j$ is (Burnham and Anderson 2002, Burnham et al. 2011). To assess the predictive performance of our RSPF models, we calculated the area under the Receiver Operating Characteristic curve, which varies between 0.5 (no predictive power) and 1 (perfect predictive power; Boyce et al. 2002).

\section{Mapping Predicted Wild Boar Distribution}

All explanatory variables considered in our model-averaged RSPF models were available as maps in ArcGIS. Therefore, we could use these variables, in combination with the model coefficients, to predict the probability of resource use by wild

Table 1. Top-ranked candidate models from multi-model inference procedure predicting feral wild boar distribution across the prairies of Saskatchewan, Canada using a social survey of community leaders $(n=110$; January 2013).

\begin{tabular}{lrrrrr}
\hline $\begin{array}{l}\text { Top-ranked } \\
\text { models }\end{array}$ & $\begin{array}{c}\text { Explanatory } \\
\text { variables }^{\mathbf{a}}\end{array}$ & $\boldsymbol{K}$ & $\mathbf{A I C}_{\boldsymbol{c}}$ & $\boldsymbol{\Delta A I C}_{\boldsymbol{c}}$ & $\mathbf{W t}$ \\
\hline 1 & $1,2,3,4,5$ & 6 & 112.78 & 0.00 & 0.60 \\
2 & $1,2,3,5$ & 5 & 113.97 & 1.19 & 0.20 \\
3 & $2,3,4,5$ & 5 & 114.06 & 1.28 & 0.19 \\
Last & 2 & 2 & 128.10 & 15.32 & 0.00 \\
\hline
\end{tabular}

${ }^{\mathrm{a}} 1=$ proportion deciduous forest; $2=$ proportion farmland; $3=$ proportion flaxseed; $4=$ proportion mustard seed; $5=$ density of paved roads. boar across the Saskatchewan rural landscape. For this we also considered those rural municipalities that did not respond to our questionnaire. To do so, we solved the RSPF with the equation

$$
\begin{array}{r}
W(x)=\exp \left(\beta_{0}+\beta_{1} \chi_{1}+\beta_{2} \chi_{2}+\cdots+\beta_{z} \chi_{z}\right) / \\
1+\exp \left(\beta_{0}+\beta_{1} \chi_{1}+\beta_{2} \chi_{2}+\cdots+\beta_{z} \chi_{z}\right)
\end{array}
$$

where $W(x)$ is the RSPF value for each rural municipality, $\beta_{0}$ is the model intercept, and $\beta_{1}$ is the coefficient for the predictive habitat variable $\chi_{1}$ of $z$ covariates (Manly et al. 2002). The RSPF map was produced with the raster calculator in ArcGIS.

\section{Perceptions of Risk}

Based on the completed surveys, we summarized and tabulated overall responses of the community leaders in Saskatchewan regarding the presence of feral wild boar and associated risks and impacts. We compared relationships between the frequencies of feral boar observations in each rural municipality with perceived risk using linear regression. We graphed mean $( \pm \mathrm{SE})$ level of concern regarding specific impacts on crops, environment, livestock, and humans.

\section{RESULTS}

\section{Feral Wild Boar Observations}

In total, 110 completed surveys were returned, resulting in an overall response rate of $37 \%$. There was no significant difference in responses to the sub-set of 6 questions between respondents and non-responders based on Mann-Whitney $U$-tests (all $P>0.05$ ). Of the respondents, $48 \%$ never observed feral boar over the past 3 years $(n=54), 48 \%$ observed boar at least occasionally $(n=53)$, and $3 \%$ did not know $(n=3)$, indicating some respondents were not confident in saying feral boar were present or absent.

Feral boar visual sightings occurred at all times, including daylight (28\%), dusk (17\%), dawn (16\%), and night (9\%). Direct sightings also occurred in all habitats, including wetlands (20\%), pasture (16\%), annual cropland (16\%), grassland $(11 \%)$, roads $(10 \%)$, forest $(7 \%)$, perennial forage crop (5\%), and lakes and ponds (3\%). Visual sightings occurred about evenly across all months: January (7\%), February (6\%), March (7\%), April (6\%), May (10\%), June (9\%), July (9\%), August (9\%), September (10\%), October (11\%), November (10\%), and December (7\%).

\section{Modeling the Spatial Distribution of Wild Boar in Saskatchewan}

Using multi-model inference, we identified 3 candidate models that explained large-scale resource use by wild boar equally well (i.e., $\Delta \mathrm{AIC}_{c}<2$; Table 1 ). Based on modelaveraging, the probability of occurrence of wild boar at the landscape scale clearly increased as the proportion of available farmland and deciduous forest increased (Fig. 2; Table 2). In contrast, the probability of occurrence decreased with increasing paved road density and proportion of area planted with flaxseed and mustard seed crops (Fig. 2; Table 2). The areas under the Receiver Operating Characteristic curve for 

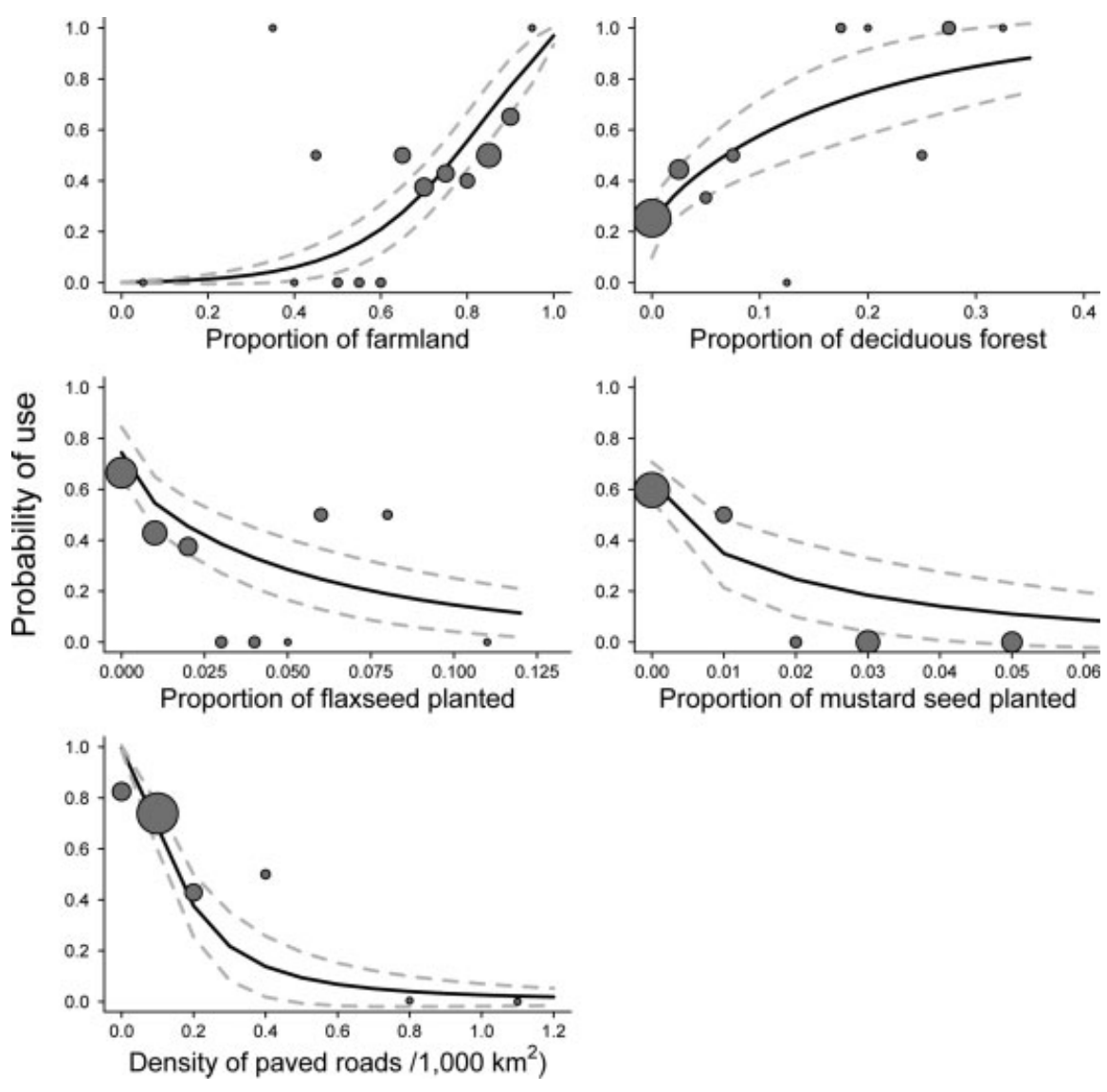

Figure 2. Effects of environmental predictor variables on the probability of use of each rural municipality by feral wild boar in the province of Saskatchewan, Canada, based on a social survey in Saskatchewan in January 2013. Symbols reflect the raw data values for each environmental variable within municipalities, with larger symbols indicating that multiple municipalities had the same value while small symbols indicate that few or only 1 municipality had that value.

the 3 top-ranked landscape-scale RSPF models were 0.798 , 0.765 , and 0.739 , respectively. Although the RSPF predicted considerable spatial variation in probability of resource use by wild boar in Saskatchewan (Fig. 1), $70 \%$ of the rural municipalities $(n=209)$ had a RSPF value of $>0.7$ (i.e., high probability of wild boar presence) and only $12 \%$ of the rural municipalities $(n=36)$ had a RSPF value of $<0.3$ (i.e., low probability of wild boar presence). Only $3 \%$ of all rural municipalities have extremely low RSPF values $<0.05$ that are unlikely to support feral wild boar.

\section{Perceptions of Risk}

The majority of respondents (ranging from $59 \%$ to $70 \%$ by type of damage) indicated that damage to bales, standing crop, pasture, and fences was "never serious" (Table 3). In

Table 2. Model-averaged $\beta$-coefficients and associated standard errors and weights for habitat variables influencing feral wild boar distribution in Saskatchewan, Canada based on a social survey of community leaders $(n=110)$ in January 2013.

\begin{tabular}{lrcc}
\hline Explanatory variables & \multicolumn{1}{c}{$\boldsymbol{\beta}$} & SE $(\mathbf{a d j})$. & $\boldsymbol{w}_{+}(\boldsymbol{j})$ \\
\hline Intercept & -9.30 & 3.53 & \\
\% Farmland & 6.46 & 2.43 & 1.0 \\
\% Flaxseed & -8.63 & 3.24 & 1.0 \\
Density of paved roads & -1.92 & 0.84 & 1.0 \\
\% Deciduous forest & 5.93 & 2.72 & 0.8 \\
\% Mustard seed & -12.63 & 5.75 & 0.8 \\
\hline
\end{tabular}

each of these questions, approximately $25 \%$ of respondents indicated "I don't know." The levels of concern $(1=$ no concern; $5=$ moderate concern; $10=$ extremely high concern) expressed by respondents regarding feral wild boar impacts were consistently moderate for all impacts on crops, livestock, humans, and the environment (Fig. 3).

There was considerable variation in Likert scale (strongly disagree to strongly agree) responses regarding perceptions of the severity of the problem and these differences were associated with whether the questions were about the local rural municipality or province as a whole (Fig. 4). Similarly, there was considerable variation in the relationship between frequency of observing feral wild boar and responses to the statements about feral wild boar concerns and options for management (Fig. 4). For questions aimed at the scale of the rural municipality, responses were positively associated with frequency of feral boar observations, whereas questions about the province as a whole were consistently positive regardless of frequency of feral boar observations. Frequency of observing feral wild boar observations was significantly positively correlated with perceptions of risk for questions related to Likert scale responses to the following statements: "feral wild boar are a critical current concern in Saskatchewan" $\left(R^{2}=0.789, P=0.02\right)$, "feral wild boar are a critical current concern in my RM" $\left(R^{2}=0.506, P<0.001\right)$; "feral wild boar will likely be a big problem in the future in my RM" 
Table 3. Perceptions of damage caused by feral wild boar in rural municipalities, as reported by community leaders in Saskatchewan, Canada based on a social survey $(n=110)$ conducted in January 2013.

\begin{tabular}{|c|c|c|c|c|c|c|}
\hline Response & Bales (field) & Bales (yard) & Standing hay & Standing grain & Pasture & Fences \\
\hline Never serious & $63 \%$ & $66 \%$ & $61 \%$ & $59 \%$ & $61 \%$ & $70 \%$ \\
\hline Seldom serious & $12 \%$ & $6 \%$ & $6 \%$ & $8 \%$ & $8 \%$ & $2 \%$ \\
\hline Serious in some years & $0 \%$ & $2 \%$ & $8 \%$ & $5 \%$ & $5 \%$ & $0 \%$ \\
\hline Serious in most years & $0 \%$ & $0 \%$ & $0 \%$ & $3 \%$ & $2 \%$ & $0 \%$ \\
\hline Serious in all years & $0 \%$ & $0 \%$ & $0 \%$ & $0 \%$ & $0 \%$ & $0 \%$ \\
\hline I don't know & $25 \%$ & $26 \%$ & $26 \%$ & $26 \%$ & $25 \%$ & $28 \%$ \\
\hline
\end{tabular}

$\left(R^{2}=0.697, P<0.001\right)$; "feral wild boar create exciting hunting opportunities" ( $\left.R^{2}=0.480, P=0.02\right)$; and "we need more action to eradicate feral wild boar in my RM $\left(R^{2}=0.696, P=0.02\right)$, but was not significant for "we need more action to eradicate feral wild boar in Saskatchewan" $\left(R^{2}=0.101, P=0.59\right)$.

\section{DISCUSSION}

This study is a first attempt at estimating the distribution and local perceptions of the socio-economic risks associated with feral wild boar presence on the western Canadian prairies. Empirical ecological data on feral wild boar movements are currently lacking in Canada so we employed a social science approach to determine the current distribution of this invasive species. This approach also provides insight into the perceived risks of wild boar presence at the community and provincial scale. Our results demonstrate that feral wild boar currently occur at varying levels of abundance throughout Saskatchewan. Presence of feral boar is positively influenced by the wide-spread abundance of agricultural land, sufficient cover in terms of deciduous forests, and a relatively low density of paved roads (a proxy for human density, human activity, and feral boar-vehicle collision risk). Only areas with specific, but relatively rare, crop types such as mustard seed and flaxseed showed a negative relationship with boar observations, which likely indicates that these crop types are less preferred food items. Feral wild boar sightings were equally consistent across seasons and periods of the day. In other areas of its range, the species is exclusively nocturnal when either human density or hunting pressure is high (Braga et al. 2010, Podgorski et al. 2013). This could suggest that feral wild boar in Saskatchewan have adjusted their behavior to local conditions, with low hunting pressure or other natural threats, which can greatly facilitate range expansion (Podgorski et al. 2013).

Despite the wide-spread distribution of feral wild boar across Saskatchewan, many rural municipalities were unaware of the risks associated with their presence or did not know what action to take in order to control potential environmental impact. Although such responses are consistent with the idea that feral wild boar are a relatively new species on the Canadian prairies, it also highlights a serious management concern. Because of the species' rapid range expansion as well as its ability to successfully reproduce in this system, the potential for severe economic and environmental impact is real and eminent, as is evident from many other regions in the world where the species has successfully established (Geisser and Reyer 2004, BarriosGarcia and Ballari 2012). In order to effectively manage this highly invasive species on the Canadian prairies, a proactive and large-scale approach is essential, which involves action from important stakeholders such as the licensed hunting community and Aboriginal people, but also includes raising awareness of the risks associated with this species (including

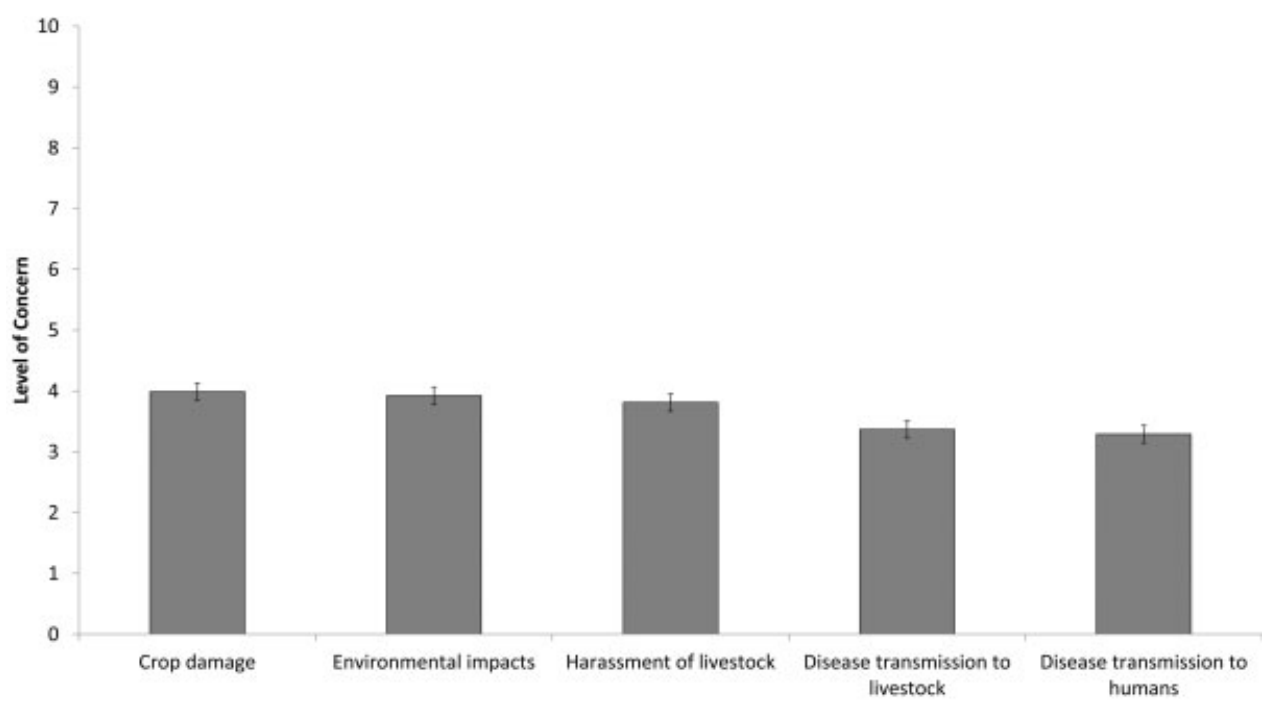

Figure 3. Levels of concern $(1=$ no concern; $5=$ moderate concern; $10=$ extremely high concern $)$ expressed by rural municipal councils regarding existing or potential impacts of feral wild boar in the province of Saskatchewan, Canada based on a survey conducted in January 2013. 


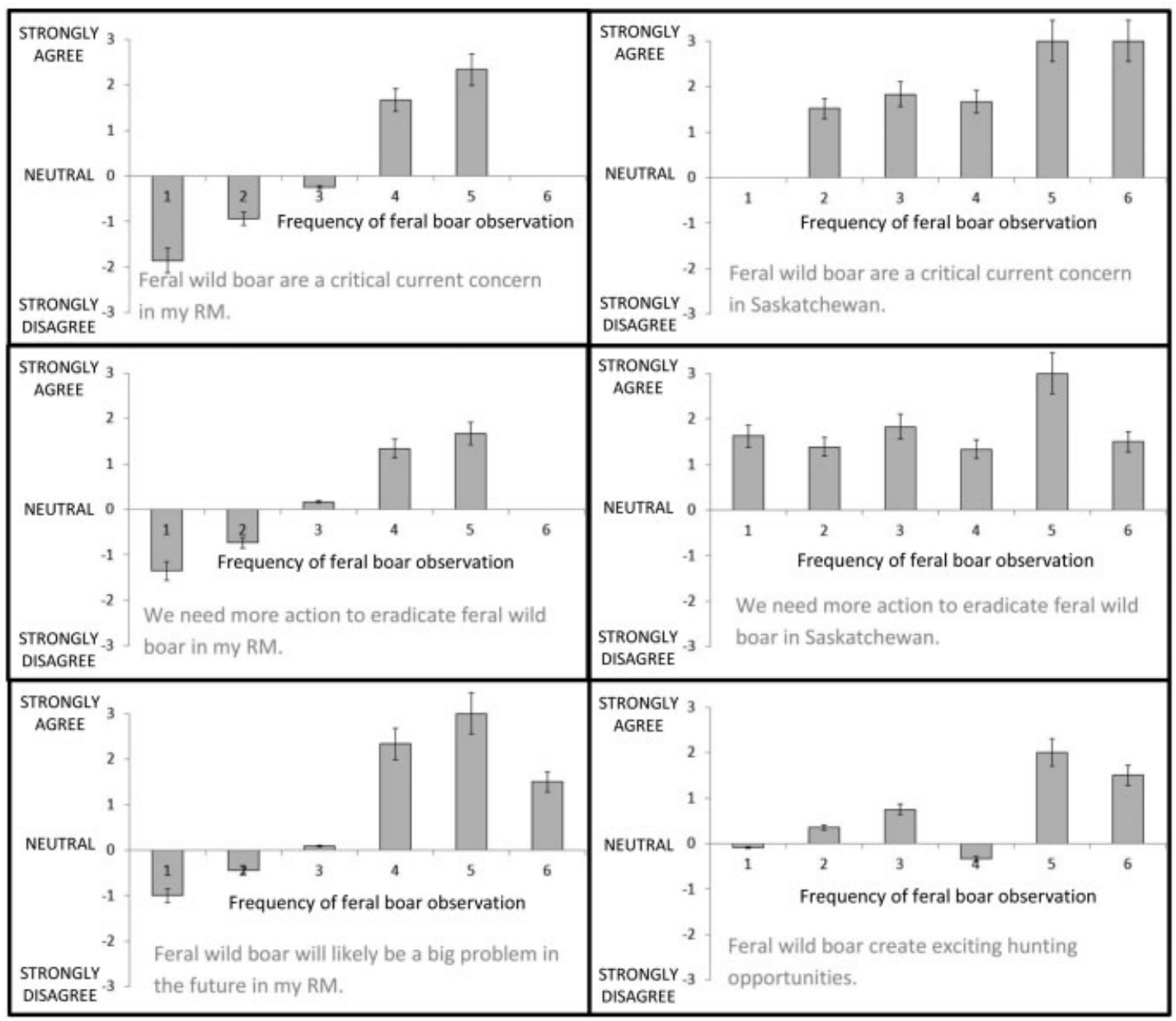

Figure 4. Relationship between frequency of feral wild boar observations by each rural municipality (RM) council (scale is $1=$ "never see," $2=$ "rarely see," 3 ="see a few only on some days," $4=$ "see a few on most days," $5=$ "see regularly on most days," $6=$ "see regularly on all days") and response to the statements about feral wild boar concerns and options for management, on a scale from "strongly disagree $=-3$ " to "strongly agree $=+3$ " in the province of Saskatchewan, Canada based on a social survey (January 2013).

disease, crop damage, and ecosystem impacts) that may affect the general public, especially in rural and remote areas. The role of domestic wild boar farms on the Canadian prairies in the expansion and maintenance of the feral wild boar population via ongoing escapes and intentional releases reflects an important topic of future research and risk mitigation.

Our results also underscore the value of incorporating both the observations and perceptions of local people in characterizing social-biological problems. Past research has validated the capacity of lay people to accurately detect and report observations of wildlife (Brook and McLachlan 2006, 2009; LaDeau et al. 2007). Social survey data have also been used successfully for other species to develop and evaluate occupancy models (Brook and McLachlan 2009, Rich et al. 2013). Referred to as either citizen science, or local or traditional knowledge depending on the source populations and methods used, observations made by large numbers of individuals working and living on large areas provide both a cost-effective and accurate way of acquiring data on species distribution (Brook and McLachlan 2009, Devictor et al. 2010). Additionally, this kind of monitoring that includes local people has the potential to effectively engage communities in helping them better understand problems in their direct surroundings in ways that conventional biological research and monitoring often fails to do (Brook and McLachlan 2008, 2009).

Although there has been a large number of ecological studies on feral boar globally, there are notably few peerreviewed publications on the social science aspects of the feral boar issue (except see Mason and Fleming 1999; Rollins et al. 2007). Engagement of local stakeholders in the feral wild boar issue is likely to improve through systematic research efforts that document the knowledge and perceptions of local people (Brook and McLachlan 2009). Convincing local people to address the feral wild boar issue and initiate and/or accept management actions will depend on how individuals perceive the social pressures that affect behavior and subsequent personal attitudes toward that behavior (i.e., subjective norms; Ajzen and Fishbein 1980). Management of feral boar must address the financial incentives and disincentives. For example the presence of the Saskatchewan Crop Insurance Corporation program, while providing immediate benefits to farmers, creates a disincentive for producers to address the problem because their crop and livestock losses due to feral boar are 
compensated at $100 \%$ of the value with no premiums required.

The results of this work provide useful data for potentially managing and/or eradicating feral boar; however, this pilot study has limitations. Although response rate was good for a survey of this type and there were no biases detected due to non-response, there remain large areas of Saskatchewan where the current status of feral boar remains unconfirmed. There is some potential for other biases in responses; for example, some respondents may be unwilling to report observations of feral wild boar if they enjoy feral boar hunting and fear that reported sightings will be used to target eradication efforts. There have been numerous media stories (newspaper, radio, television) in recent years and these likely affect the responses of participants. Perhaps of greatest concern is the possibility of false negatives in municipalities where feral boar are present but not detected. Where the status has been established through this survey, it is likely that further corroborating evidence is needed because rural municipalities are large and feral boar are known to be elusive and difficult to detect (Massei et al. 1997, 2011; Lemel et al. 2003). Although participants in our study did report seeing feral boar, it is likely that these observations represent only a fraction of the total number present in the province and the overall distribution of feral boar is likely even more widespread than presented here. However, we feel that our results have merit given that we identified important differences between rural municipalities that have observed feral wild boar and those RMs that have not yet seen feral boar, and these differences are generally consistent with expectations based on studies of feral boar in other countries (Barrios-Garcia and Ballari 2012).

There have been small-scale and short term efforts to remove feral wild boar in parts of Saskatchewan through local grassroots efforts, individual hunters in the province, and the program administered by the Saskatchewan Association of Rural Municipalities, so it is possible that some of these rural municipalities that were identified as having feral boar now do not have any. However, given the low level of efforts at control and, the scale of feral boar distribution, this seems unlikely, especially over the long term (i.e., years and decades). Given the reproductive and dispersal capacity of feral wild boar (Barrios-Garcia and Ballari 2012), combined with minimal (at best) efforts to control them on the Canadian prairies, population growth and expansion is most likely to continue. Perhaps of greatest concern on the Canadian prairies, is the risk of disease transmission from feral boar to livestock, but very little is currently know about interactions and disease risks at the feral boar-livestock interface. More work is needed using diverse approaches, including both social and biological research and both large- and small-scale monitoring, to better understand the distribution, abundance, and socioeconomic impacts of feral wild boar.

\section{MANAGEMENT IMPLICATIONS}

The distribution and abundance of feral wild boar has increased dramatically across the western Canadian prairies to the point that the species should now be considered an endemic invasive species and eradication is no longer realistic. Prior to this current study, there were no peerreviewed studies of feral boar in Canada. Existing information on feral boar distribution on the western Canadian prairies has been based only on ad hoc reports of feral wild boar from various sources and there has never been a systematic approach to seeking or documenting sightings, characterizing community perceptions of risk, or predicting overall distributions. Future research should aim at quantifying finer scale distribution and habitat use as well as monitoring domestic and feral wild boar to more effectively coordinate control measures. Although there have been relatively few documented cases of localized impacts of feral boar, the distribution and abundance of feral boar strongly suggests that significant socio-economic problems are imminent.

To effectively control impacts associated with crop damage, harassment of livestock, loss of native biodiversity, and risk of disease transmission to livestock, control efforts must intensify, increase in scope and scale, and engage the public. Despite clear and strong evidence from other regions that hunting alone is not successful at controlling feral boar or even reducing population size in many areas, there appears to be a widespread assumption in western Canada that hunting alone is a viable solution. More realistic control options include ground-trapping, coordinated harvest by trained teams, hunting with dogs, aerial hunting with airplanes and helicopters, use of Judas pigs, and fencing (McIlroy and Gifford 1997, Geisser and Reyer 2004). To be effective, these approaches must be coordinated and focused across all areas, especially those at highest risk. An essential element of effective management will be cost-effective up to date, and reliable mapping of feral boar distribution and abundance.

\section{ACKNOWLEDGMENTS}

Thanks to D. Harvey and A. Kozak at the Saskatchewan Association of Rural Municipalities for guidance and support in administering the surveys. M. Ives and J. Porter at the Saskatchewan Institute of Applied Science and Technology kindly entered all of the data. The Wildlife Ecology and Community Engagement Lab and Eric Vander Wal provided on-going input and support and Anja Sorensen helped with data analysis. We especially acknowledge the many rural municipality councils that took the time to complete the surveys. This work was funded by the University of Saskatchewan through the Natural Sciences and Engineering Research Council of Canada President's Fund, the Cyril Capling Trust Fund, and a research start-up grant to RKB.

\section{LITERATURE CITED}

Ajzen, I., and M. Fishbein. 1980. Understanding attitudes and predicting social behavior. Prentice-Hall, Upper Saddle River, New Jersey, USA.

Barrios-Garcia, M., and S. A. Ballari. 2012. Impact of wild boar (Sus scrofa) in its introduced and native range: a review. Biological Invasions 14: 2283-2300.

Beyer, H. L. 2012. Geospatial modelling environment. < http://www. spatialecology.com/gme >. Accessed 28 Jun 2013. 
Boyce, M. S., P. R. Vernier, S. E. Nielsen, and F. K. A. Schmiegelow. 2002. Evaluating resource selection functions. Ecological Modelling 157:281300.

Braga, C., N. Alexandre, P. Fernandez-Llario, and P. Santos. 2010. Wild boar (Sus scrofa) harvesting using the espera hunting method: side effects and management implications. European Journal of Wildlife Research $56: 465-469$.

Brook, R. K., and S. M. McLachlan. 2006. Factors influencing farmers' concerns associated with bovine tuberculosis in wildlife and livestock around Riding Mountain National Park, Manitoba, Canada. Journal of Environmental Management 80:156-166.

Brook, R. K., and S. M. McLachlan. 2008. Trends and prospects for local knowledge in ecological and conservation research and monitoring. Biodiversity and Conservation 17:3501-3512.

Brook, R. K., and S. M. McLachlan. 2009. Transdisciplinary habitat models for elk and cattle as a proxy for bovine tuberculosis transmission risk. Preventive Veterinary Medicine 91:197-208.

Burnham, K. P., and D. R. Anderson. 2002. Model selection and multimodel inference: a practical information-theoretic approach. Second edition. Springer-Verlag, New York, New York, USA.

Burnham, K. P., D. R. Anderson, and K. P. Huyvaert. 2011. AIC model selection and multimodel inference in behavioral ecology: some background, observations, and comparisons. Behavioral Ecology and Sociobiology 65:23-35.

Cooper, S. E., C. K. Nielsen, and P. T. McDonald. 2012. Landscape factors affecting relative abundance of gray foxes Urocyon cinereoargenteus at large scales in Illinois, USA. Wildlife Biology 18:366-373.

Crawley, M. J. 2007. The R book. John Wiley \& Sons, Chichester, England, United Kingdom.

Devictor, V., R. J. Whittaker, and C. Beltrame. 2010. Beyond scarcity: citizen science programmes as useful tools for conservation biogeography. Diversity and Distributions 16:354-362.

Forrester, D. J. 1991. Parasites and diseases of wild mammals in Florida. University of Florida Press, Gainesville, Florida, USA.

Geisser, H., and H. U. Reyer. 2004. Efficacy of hunting, feeding, and fencing to reduce crop damage by wild boars. Journal of Wildlife Management 68:939-946.

Gipson, P. S., B. Hlavachick, and T. Berger. 1998. Range expansion by wild hogs across the central United States. Wildlife Society Bulletin 26:279286.

Hone, J. 2002. Feral pigs in Namadgi National Park, Australia: dynamics, impacts and management. Biological Conservation 105:231-242.

Johnson, D. H. 1980. The comparison of usage and availability measurements for evaluating resource preference. Ecology 61:65-71.

Jolley, D. B., S. S. Ditchkoff, B. D. Sparklin, L. B. Hanson, M. S. Mitchell, and J. B. Grand. 2010. Estimate of herpetofauna depredation by a population of wild pigs. Journal of Mammalogy 91:519-524.

LaDeau, S. L., A. M. Kilpatrick, and P. P. Marra. 2007. West Nile virus emergence and large-scale declines of North American bird populations. Nature 447:710-713.

Lemel, J., J. Truvé, and B. Söderberg. 2003. Variation in ranging and activity behavior of European wild boar Sus scrofa in Sweden. Wildlife Biology 9:29-36.

Leus, O. W. 2008. Sus scrofa. Red list of threatened species. Version 2009.1. $<$ http://www.iucnredlist.org $>$. Accessed 6 Sep 2012.

MacKenzie, D. I. 2006. Modeling the probability of resource use: the effect of, and dealing with, detecting a species imperfectly. Journal of Wildlife Management 70:367-374.

Manly, B. F. J., L. L. McDonald, D. L. Thomas, T. L. McDonald, and W. P. Erickson. 2002. Resource selection by animals: statistical analysis and design for field studies. Volume 2. Kluwer Academic, Dordrecht, The Netherlands.

Mason, R. J., and P. J. S. Fleming. 1999. Australian hunters and the surveillance of feral pigs for exotic diseases. Wildlife Society Bulletin 27:395-402.

Massei, G., P. Genov, B. Staines, and M. L. Gorman. 1997. Factors influencing home range and activity of wild boar (Sus scrofa L.) in a Mediterranean coastal area. Journal of Zoology London 242:411-423.

Massei, G., S. Roy, and R. Buting. 2011. Too many hogs? A review of methods to mitigate impact by wild boar and feral hogs. Human-Wildlife Interactions 5:79-99.

McIlroy, J. C., and E. J. Gifford. 1997. The 'Judas' pig technique: a method that could enhance control programmes against feral pigs, Sus scrofa. Wildlife Research 24:483-491.
Podgorski, T., G. Bas, B. Jedrezejewska, L. Sonnichesen, S. Sniezko, W. Jedrzejewski, and H. Okarma. 2013. Spatiotemporal behavioral plasticity of wild boar (Sus scrofa) under contrasting conditions of human pressure: primeval forest and metropolitan area. Journal of Mammalogy 94:109119.

R Development Core Team. 2013. R: a language and environment for statistical computing. R Foundation for Statistical Computing, Vienna, Austria.

Rich, L. N., R. E. Russell, E. M. Glenn, M. S. Mitchell, J. A. Gude, K. M. Podruzny, C. A. Sime, K. Laudon, D. E. Ausband, and J. D. Nichols. 2013. Estimating occupancy and predicting numbers of gray wolf packs in Montana using hunter surveys. Journal of Wildlife Management 77:1280-1289.

Roe, E. 1996. Why ecosystem management can't work without social science: an example from the California northern spotted owl controversy. Environmental Management 20:667-674.

Rollins, D., B. J. Higginbotham, K. A. Cearly, and R. N. Wilkins. 2007. Appreciating feral hogs: extension education for diverse stakeholders in Texas. Human-Wildlife Conflicts 1:192-198.

Samson, F., and F. Knopf. 1994. Prairie conservation in North America. BioScience 44:418-421.

Samuel, W. M., M. J. Pybus, A. A. Kocan. editors. 2001. Parasitic diseases of wild mammals. Iowa State University Press, Ames, USA.

Saskatchewan Ministry of Agriculture. 2001. Wild boar production: Economic and production information for Saskatchewan producers. http://hartkeisonline.com/wp-content/uploads/WildBoarProduction0111. pdf

Schley, L., and T. J. Roper. 2003. Diet of wild boar Sus scrofa in Western Europe, with particular reference to consumption of agricultural crops. Mammal Review 33:43-56.

Statistics Canada. 2011. 2011 census of agriculture. <http://www.statcan. gc.ca/ca-ra2011/index-eng.htm >. Accessed 28 Jun 2013.

Tegt, J., J. Mayer, J. Dunlap, and S. Ditchkoff. 2011. Plowing through North America: wild pigs leave a trail of depredation and disease. The Wildlife Professional 5:36-39.

Thomas, D. L., and E. J. Taylor. 2006. Study designs and tests for comparing resource use and availability II. Journal of Wildlife Management 70:324-336.

Towne, C. W., and E. N. Wentworth. 1950. Pigs from cave to cornbelt. University of Oklahoma Press, Norman, USA.

U.S. Department of Agriculture and Animal and Plant Health Inspection Service [USDA-APHIS]. 2005. Feral swine: damage and disease threats. $<$ www.aphis.usda.gov/publications >. Accessed 2 Jul 2013.

van Beest, F. M., E. Vander Wal, A. V. Stronen, P. C. Paquet, and R. K. Brook. 2013. Temporal variation in site fidelity: scale-dependent effects of forage abundance and predation risk in a non-migratory large herbivore. Oecologia 173:409-420.

Veeman, T. S., and R. Gray. 2009. Agricultural production and productivity in Canada. Choices 24:1-8.

Walker, B., C. S. Holling, S. R. Carpenter, and A. Kinzig. 2004. Resilience, adaptability and transformability in social-ecological systems. Ecology and Society 9:5.

Wilkins, W., and S. Dobbs. 2013. Have you seen feral wild boar? < http:// www.agriculture.gov.sk.ca/agv1212-pg11>. Accessed 2 Jul 2013.

Witmer, G. W., R. S. Sanders, and A. C. Taft. 2003. Feral swine-are they a disease threat to livestock in the United States. Pages 316-325 in K. A. Fagerstone, and G. W. Witmer, editors. Proceedings of the 10th wildlife damage management conference. The Wildlife Damage Management Working Group of The Wildlife Society, Fort Collins, Colorado, USA.

Associate Editor: Rodgers.

\section{SUPPORTING INFORMATION}

Additional supporting information may be found in the online version of this article at the publisher's web-site.

The questionnaire used to determine the distribution of feral wild boar in Saskatchewan and associated perceptions of community leaders. 